\title{
Characterizing evolving frameworks: issues from Esmail et al. (2020) review
}

Russell E. Glasgow ${ }^{1,2^{*}}$ (D, Paul A. Estabrooks ${ }^{3}$ and Marcia G. Ory ${ }^{4,5,6}$

\begin{abstract}
There are complex issues in understanding and categorizing implementation science theories, models, and frameworks. Systematic reviews of these models are important undertakings for synthesizing current knowledge. The issues involved are even more challenging when reviewing a large number of frameworks and when some of the frameworks have evolved significantly over time. This paper addresses how the RE-AIM (Reach, Effectiveness, Adoption, Implementation, and Maintenance) framework was described in the recent Esmail (2020) review and identifies four mischaracterizations. This is followed by a more general discussion of how advances or extensions of frameworks after an original source publication or influential review tend to be overlooked. We discuss why inadvertent mischaracterization of what a framework is and is not, and what it can and cannot be used for, can have deleterious consequences. Finally, we suggest initial ideas about what could be done to prevent or alleviate some of these problems by reviewers, framework developers, and scholars at large.
\end{abstract}

Keywords: Review, RE-AIM, Implementation science framework, Classification

We are writing concerning the recent review article by Esmail et al. "A scoping review of full-spectrum knowledge translation theories, models, and frameworks" in Implementation Science [1]. While we see this article as making an important contribution to the literature, it also, likely inadvertently, mischaracterized the RE-AIM framework in a few salient areas. Our intent is to provide some clarity on these areas, highlight the implications of mischaracterizations of theories, models, and frameworks (TMF), and offer ideas for positive solutions that can advance implementation science.

It is important to start with the potential source of mischaracterizations related to the RE-AIM framework.

This comment refers to the article available at https://doi.org/10.1186/ s13012-020-01010-1.

* Correspondence: russell.glasgow@cuanschutz.edu

${ }^{1}$ Family Medicine, University of Colorado School of Medicine, $13199 \mathrm{E}$. Montview Blvd, Aurora, CO 80045, USA

${ }^{2}$ Dissemination and Implementation Science Program of ACCORDS (Adult and Child Consortium for Health, University of Colorado School of Medicine, 13199 E. Montview Blvd, Aurora, CO 80045, USA

Full list of author information is available at the end of the article
The only RE-AIM reference cited in the review article was the original 1999 citation [2]. The RE-AIM framework like many others has evolved considerably over the past 20 years. Since 1999, we have published several reviews, updates, modifications, newer applications, and guidance for use of RE-AIM [3, 4]. In brief, four of the statements made about RE-AIM are incorrect, some were partially correct up until 2013, but others have not been accurate for the past decade or more. Below, we summarize the mischaracterizations, followed by a more accurate statement about the RE-AIM framework:

1. The RE-AIM framework is solely quantitative in nature. There have been reports of qualitative uses of RE-AIM for at least a decade. Qualitative assessments of reasons why RE-AIM results were found have been recommended in published reviews since at least 2013 and explicitly called out as a strong recommendation in Kessler et al. [5].

2. RE-AIM assumes all dimensions are equally important. All RE-AIM dimensions are important 
and contribute to overall public health impact. However, since 2006 [6], we have discussed pros and cons of different weightings of RE-AIM elements. We advise users to consider all elements, but to prioritize the dimensions most important to stakeholders in a given project [7].

3. The time interval for assessing implementation and maintenance are arbitrary. The time interval for implementation and maintenance are not arbitrarily mandated to be 6 months and 2 years, respectively. In our first publication on RE-AIM in 1999 [2], this was the case, but in many articles since then, the framework and these temporal perspectives have evolved-e.g., from sustained implementation directly after grant funding ceases to as long as 5 years after the initial implementation was completed [8].

4. The RE-AIM framework is only an evaluation framework. RE-AIM is not just an evaluation framework. It has been widely and successfully used to plan interventions for almost 15 years [9] and, more recently, to help guide adaptations during implementation. In addition, the PRISM framework which includes RE-AIM was added in 2008 [10] to address contextual factors that impact RE-AIM outcomes.

What promoted this letter is that similar miscategorization and statements that RE-AIM is only an evaluation framework, cannot be used for any other purpose, is not an implementation model, or cannot be used as a qualitative approach are often heard from grant and journal article reviewers despite abundant evidence to the contrary. These inaccurate assertions have had negative impacts on advancing science and on the evaluation of proposals of several promising emerging researchers.

We take partial responsibility for this situation, since our group has not consistently provided clear guidance or unambiguous statements on these issues. Although we try to keep our website [3] current, there have been inconsistencies on the website, and as discussed above, the model has and continues to evolve. We have recently published the Glasgow et al. [4] paper to more clearly describe what is now Expanded RE-AIM/PRISM, the meaning and distinctions among various RE-AIM dimensions, and provide guidance on related issues.

Our larger concern is that similar mischaracterization issues apply not only to RE-AIM, but also to other TMFs. From discussions with other TMF developers, we speculate that many reviewers and scientists rely only on either (a) the original TMF article without considering refinements and extensions over time or (b) an influential review, or even increasingly reviews of reviews. We understand that when reviewing the broad range of TMFs, it is not possible to review the entire literature on each TMF, but conclusions in major publications have consequences.

Beyond specific issues concerning RE-AIM, we would like to begin discussion of how the field can collectively prevent or address unintended consequences of earlier categorizations or initial TMF papers being cited as conclusive without considering additional literature. We recommend that discussion sections of reviews include a highlighted statement that not all studies on each TMF were evaluated, that there may have been changes since an original publication on a given TMF, and that readers should not rely solely on that review and/or the original reference. We welcome other suggestions on what reviewers, TMF developers, and readers can do to alleviate this troubling and relatively common issue.

\section{Abbreviations}

RE-AIM: Reach, Effectiveness, Adoption, Implementation, and Maintenance; TMF: Theories, models, and frameworks; PRISM: Practical, Robust, Implementation, and Sustainability Model

\section{Acknowledgements \\ None}

\section{Authors' contributions}

$R G, P E$, and $M O$ worked in collaboration to draft and finalize this letter to the editor. The authors read and approved the final manuscript.

\section{Authors' information}

Russell Glasgow, PhD, is the Director of the Dissemination and Implementation Program of ACCORDS and research professor in the Department of Family Medicine at the University of Colorado School of Medicine. Prior to Fall 2013, he was Deputy Director for Implementation Science in the Division of Cancer Control and Population Science at the US National Cancer Institute. Dr. Glasgow is one of the original developers of the RE-AIM and PRISM frameworks.

He is an implementation scientist whose recent work has focused on public health issues of enhancing the reach and adoption of evidence-based programs, adaptation and context, and pragmatic research methods and measures to enhance health equity and sustainment. He currently focuses much of his time on mentoring, training, and building capacity in implementation science

Paul Estabrooks, PhD, is the Harold M. Maurer Distinguished Chair of Health Promotion in the College of Public Health at the University of Nebraska Medical Center. He is a founding member of the RE-AIM Workgroup who focuses on community and clinical adoption, implementation, and maintenance of evidence-based nutrition, physical activity, and weight control interventions.

Marcia G. Ory, PhD, MPH, is Regents and Distinguished Professor at Texas A\&M University School of Public Health -College Station Texas, and Founding Director of the university-wide Center for Population Health and Aging. She was first engaged in promoting RE-AIM in the early 2000s as a program director at the National Institute on Aging and currently instrumental as a founding member of the national workgroup on RE-AIM Planning and Evaluation Framework in disseminating RE-AIM as a planning and evaluation tool throughout the aging services network.

Funding

$\mathrm{NCl}$ grant 1P50CA244688-01

Availability of data and materials N/A

Ethics approval and consent to participate N/A 


\section{Consent for publication}

N/A

\section{Competing interests}

This letter to the editor was written by members of the RE-AIM workgroup.

\section{Author details}

${ }^{1}$ Family Medicine, University of Colorado School of Medicine, $13199 \mathrm{E}$ Montview Blvd, Aurora, CO 80045, USA. ${ }^{2}$ Dissemination and Implementation Science Program of ACCORDS (Adult and Child Consortium for Health, University of Colorado School of Medicine, 13199 E. Montview Blvd, Aurora, CO 80045, USA. ${ }^{3}$ College of Public Health,Department of Health Promotion, University of Nebraska Medical Center, 986075 Nebraska Medical Center, Omaha, NE 68198-6075, USA. " Environmental and Occupational Health, School of Public Health, Texas A\&M University, SPH Administration Building, 212 Adriance Lab Rd., TAMU BIdg \#1518 | TAMU MS 1266, College Station, TX 77843, USA. ${ }^{5}$ Center for Population Health and Aging, Texas A\&M University, SPH Administration Building, 212 Adriance Lab Rd., TAMU Bldg \#1518 | TAMU MS 1266, College Station, TX 77843, USA. ${ }^{6}$ Strategic Partnerships and Initiatives, Texas A\&M Health, Texas A\&M University, SPH Administration Building, 212 Adriance Lab Rd., TAMU BIdg \#1518 | TAMU MS 1266, College Station, TX 77843, USA.

Received: 7 May 2020 Accepted: 12 June 2020

Published online: 02 July 2020

\section{References}

1. Esmail R, Hanson HM, Holroyd-Leduc J, Brown S, Strifler L, Straus SE, et al. A scoping review of full-spectrum knowledge translation theories, models, and frameworks. Implement Sci. 2020;15(1):11.

2. Glasgow RE, Vogt TM, Boles SM. Evaluating the public health impact of health promotion interventions: the RE-AIM framework. Am J Public Health. 1999:89(9):1322-7.

3. Available from: www.re-aim.org.

4. Glasgow RE, Harden SM, Gaglio B, Rabin B, Smith ML, Porter GC, et al. REAlM planning and evaluation framework: adapting to new science and practice with a 20-year review. Front Public Health. 2019;7:64.

5. Kessler RS, Purcell EP, Glasgow RE, Klesges LM, Benkeser RM, Peek CJ. What does it mean to "employ" the RE-AIM model? Eval Health Prof. 2013;36(1): 44-66.

6. Glasgow RE, Klesges LM, Dzewaltowski DA, Estabrooks PA, Vogt TM. Evaluating the impact of health promotion programs: using the RE-AIM framework to form summary measures for decision making involving complex issues. Health Educ Res. 2006;21(5):688-94.

7. Glasgow RE, Estabrooks PE. Pragmatic applications of RE-AIM for health care initiatives in community and clinical settings. Prev Chronic Dis. 2018;15:E02.

8. Estabrooks PA, Bradshaw M, Dzewaltowski DA, Smith-Ray RL. Determining the impact of Walk Kansas: applying a team-building approach to community physical activity promotion. Ann Behav Med. 2008;36(1):1-12.

9. Klesges LM, Estabrooks PA, Dzewaltowski DA, Bull SS, Glasgow RE. Beginning with the application in mind: designing and planning health behavior change interventions to enhance dissemination. Annals of Behavioral Medicine. 2005;29(2):66-75.

10. Feldstein AC, Glasgow RE. A practical, robust implementation and sustainability model (PRISM) for integrating research findings into practice. Jt Comm J Qual Patient Saf. 2008;34(4):228-43.

\section{Publisher's Note}

Springer Nature remains neutral with regard to jurisdictional claims in published maps and institutional affiliations.

Ready to submit your research? Choose BMC and benefit from:

- fast, convenient online submission

- thorough peer review by experienced researchers in your field

- rapid publication on acceptance

- support for research data, including large and complex data types

- gold Open Access which fosters wider collaboration and increased citations

- maximum visibility for your research: over $100 \mathrm{M}$ website views per year

At $\mathrm{BMC}$, research is always in progress.

Learn more biomedcentral.com/submissions 